\title{
Interior Space Design of Community Activity Center Based on Service Function
}

\author{
Fengyan Shao \\ College of Urban Planning and Architecture, Southwest Minzu University, Chengdu, China \\ Email: 1060987581@qq.com
}

How to cite this paper: Shao, F.Y. (2019) Interior Space Design of Community Activity Center Based on Service Function. Open Journal of Social Sciences, 7, 209-214. https://doi.org/10.4236/jss.2019.75017

Received: April 2, 2019

Accepted: May 21, 2019

Published: May 24, 2019

Copyright () 2019 by author(s) and Scientific Research Publishing Inc. This work is licensed under the Creative Commons Attribution International License (CC BY 4.0).

http://creativecommons.org/licenses/by/4.0/

\begin{abstract}
Community activity center is a public space to serve the community masses, which is also the purpose of its existence. The function of community activity center will be adjusted according to the different service population, so the determination of service population and demand is the key to the division and layout of spatial function. This article takes the community service crowd as the breakthrough point, analyzes the different behavior pattern and the use demand of the service crowd, carries on the interior space design to the community activity center based on the service function, promotes the design of public space and the construction of spiritual civilization in the community, and serves the people of the community to live and work in peace and contentment.
\end{abstract}

\section{Keywords}

Community Activity Center, Public Space, Function Demand Design

\section{Introduction}

Nowadays, the community activity centers in many cities have certain functional space and public facilities, but not all public spaces can meet the needs of certain users. In the so-called community activity center, that is, in the community or community group, there is an open space body between the building entities. It is an open place for community residents to carry out public exchanges and hold various activities [1]. In the community activity center public space planning and design, designers need to focus on the needs and functions in the spatial design of the corresponding, comprehensive consideration and then create a comfortable and pleasant environment for community residents to live.

\section{Determination of Service Population and Demand}

The community activity center provides residents with a comprehensive place 
for leisure, entertainment and cultural activities, which is equivalent to the "public living room" of residential areas. This "living room" takes the residents of the residential area as the main service object, and sometimes also faces the residents outside the residential area [2]. This space can be regarded as a multi-level and diverse social organization space, which can become a social hub for residents to live together by organizing, guiding, educating and condensing the public life of the residents in the jurisdiction. So that residents have a sense of dependence and belonging to the recreational life and collective activities of community activity centers. Promote the design of public space, promote the construction of spiritual civilization in the community, and serve the people of the community to live and work in peace and contentment.

In China, the urban residential area has experienced five forms of changes: Luli system, Lifang system, street system, neighborhood unit system and community system. Nowadays, the main living mode of our country is mainly commercial housing, and the residential area has become the basic unit of the social structure. As the material carrier of community public activities, community activity center has become the core part of community construction, and has played an extremely important role in the process of building a harmonious society. At the same time, Community activity center is not only the public facilities of the community, but also the main body of community management. Its functions and responsibilities are becoming more and more important to the community and urban development [3].

In contrast, in foreign countries, the construction of community activity centers has long spread throughout the city, among which, the construction of community activity centers in the United States is more mature than other countries. In the United States, almost every community has a community activity center in its jurisdiction, and each community activity center has its own unique regional culture and style characteristics. Through long-term practice accumulation and continuous innovation in design, they have created a variety of core models of community activity centers, each of which also has its own corresponding community activity center space to meet the needs of certain users. For example, the new Abbotts Creek Community Center in the United States, with the theme of health, includes a basic multi-function room, an activity room, a gym with teaching aids, a free fitness space, a standard basketball court and a volleyball court, to provide comprehensive and humanized public services to residents under their jurisdiction. Foreign community activity center buildings have their own characteristics, the per capita use of architectural space is large, the number is also more, coupled with the recognition and attention of many countries to public cultural activities, relatively speaking, the number of cultural buildings is large and the service radius is small. This provides a lot of convenience for the local residents in terms of life. Foreign local governments also pay special attention to the application of regional culture, ecological nature, energy saving and environmental protection in the construction of community 
activity centers.

\section{Analysis of Behavior Patterns and Use Needs of Service Population}

Community residents are the first element of a community. Without residents, there can be no so-called community, and community residents have different characteristics, such as age, sex, occupation and comprehensive literacy. Then the community activity center needs to meet the different needs of different groups of people for public space. The following is a brief analysis of the needs of different groups of people.

\subsection{Analysis of Behavior Patterns and Use Needs of the Elderly}

With the acceleration of the aging process of the global population, China has also entered an aging society. The life of the elderly is becoming more and more rich. The space provided by the community for the elderly has gradually become the most important place for the activities of the majority of the elderly. When people enter old age, the various functions of the body have been degraded accordingly. The physical decline has had a lot of life effects on the elderly. Due to the decline in their hearing and eyesight, the noise generated by the surrounding environment during daily rest can also affect the sleep quality of the elderly. This space carries the important task of most elderly people's physical exercise, communication and entertainment and other activities. Therefore, the environment of this space has a direct impact on the quality of life of the elderly in the public space [4]. The needs of the elderly to use public space are mainly reflected in the adaptability to the environment brought about by sense of security and comfort, service groups to help bring about a sense of belonging and privacy.

\subsection{Analysis of Adolescents' Behavior Patterns and Use Needs}

Most of the services provided by the community to young people are mainly 04:30 care services and weekend leisure and entertainment. According to the different needs of different students, interior design is divided into different spaces to provide students with homework, entertainment, reading, communication and other activities. If it is a large space, can't meet the division of entities of the independent space provided to students, it is necessary to pay more attention to the management of regional division and the maintenance of order. Students need to have a learning atmosphere but not too rigorous space, parents need safe and reliable facilities to safely send their children here. Only by solving the above needs can we achieve the ideal public space.

\subsection{Analysis of Behavior Patterns and Use Needs of Other Populations with Special Needs}

In addition to the above groups, the users of the community activity center also have some special groups-disabled people. The work of the disabled in the dis- 
trict is an important work content for the community, and it is also a new work field of urban community construction in our country. Today, in order to implement the leadership thinking with Xi Jinping at the core, and around the goal of building a well-off society in an all-round way and building a harmonious society, efforts have been made to solve the most concerned and direct interests of the disabled. At present, there are more than 20 million disabled people living in urban communities in China, they also need to contact the outside society, feel the rapid development of society under the Internet big data. Therefore, the community needs to provide corresponding services for the disabled and build space suitable for the activities of the disabled, which is conducive to strengthening the building of socialist spiritual civilization and constantly meeting the growing material and spiritual needs of the vast number of disabled people. It was important to promote the equal participation of persons with disabilities in social life.

\section{Division Principle of Interior Space in Community Activity Center}

Community activity centres are a large space that covers the needs of different groups of people, so the following principles should be followed in the division of space:

First, the functional principle, that is, the large space needs to be composed of different spatial forms, each space needs to meet the needs of different groups of people. For example, young people in the community need dynamic and static functional space to meet the needs of reading learning-based static space and playful dynamic space, and these two spaces should be reasonably designed through certain spatial processing techniques.

Second, the principle of economic applicability, the community is facing the general public, the planning and design of space is not high-end luxury can satisfy the people, the division of each space and the overall design of the key lies in whether it is humanized, whether the planning is scientific and reasonable, and whether it can meet the needs of the community residents.

Third, the principle of artistic aesthetics, the design of public space in the community should not only pay attention to science and rationality, but also pay attention to the artistry of design. At the same time, it is necessary to reflect certain aesthetic principles and create a novel one while paying attention to material and technical means.

Fourth, the principle of culture, community activity center is a good place to spread excellent culture, in the process of space division and design, into more meaningful and characteristic culture, It is not only a good means of communication, but also can make the public environment in the community more cultural. The Binhu Pearl Community in Hefei City, China, has organized and carried out "traditional Culture propaganda and Exhibition activities" in the library of the Community activity Center, showing the classic family style and family 
instructions, displaying calligraphy enthusiasts' calligraphy and painting, and updating more traditional cultural books, performance of traditional oriental musical instruments, performance of tea, etc. The construction of "family style and family instruction" as the theme of the cultural corridor, through the community activity center as a medium to spread culture to the residents, to create a positive learning atmosphere, has been recognized and praised by the residents under the jurisdiction.

Fifth, the principle of sustainable development, community development needs to be applied to the residents of the area for a long time, in the spatial division and environmental design, designers need to fully consider the sustainable development of community operation.

\section{Spatial Layout of Community Activity Centers Based on Service Functions}

The functional layout of community public space is a form of division of a space, which is a form of spatial layout based on the different needs of users on the premise of the function of each subspace. The division of the functional space of the community activity center also has a certain purpose. The community needs to create a comfortable and livable environment, and according to the different functional space, the different small spaces that can be created have different effects, and meet the needs of education, fitness, communication and entertainment in terms of function. And the architectural appearance or place design is to achieve affinity, a sense of belonging, inclusive and geographical, the atmosphere needs to be comfortable and quiet.

In order to achieve a sense of orderly order and logic, the community public space needs to be carefully studied in the division of functional space, according to the services that the community can provide, and then according to the design principles to divide the functional space. After the functional space meets the standard, the effective management of the community is also essential. Although the public space is the area that provides the residents' free activity and entertainment, the conventional management and organization is the work of the community operators. Only by doing a good job of the effective management and operation of each space, the community public space will reflect its role of sustainable development.

\section{Conclusion}

The external embodiment of design is the intuitive feeling of public space. The first impression of this form is very important. Just like the communication between people, the first impression left to others is also very important. Then in the design of public space, the appearance of the whole space effect to leave the first impression is also crucial. The beautification of the public space is to use all the available space, using different design techniques and forms, to create a unique atmosphere and feeling. Modern decorative techniques and methods are 
diverse. In the future, the design is more inclined to combine soft and hard materials, and the cold and warm colors are properly matched, while using innovative materials to give users a new experience.

\section{Conflicts of Interest}

The author declares no conflicts of interest regarding the publication of this paper.

\section{References}

[1] Dong, Q. (2014) Research on the Participation of Social Organizations in Community Governance. Nanjing Agricultural University, Nanjing.

[2] Roland (2013) Research on Modeling Design of Public Green Building in Small and Medium-Sized Community. Central Academy of Fine Arts, Beijing.

[3] Huang, Z. (2011) Study on the Planning and Construction of Community Center in Newly-Built Areas of Nanjing. Nanjing University, Nanjing.

[4] Tong, J.S. (2004) Analysis on the Public Space Environment of Urban elderly Community. Professional Households, No. 11, 40. 